\title{
A review of multivariate social vulnerability methodologies: a case study of the River Parrett catchment, UK
}

\author{
I. Willis ${ }^{1}$ and J. Fitton ${ }^{2}$ \\ ${ }^{1}$ Birkbeck, University of London, London, UK \\ ${ }^{2}$ University of Glasgow, Glasgow, UK \\ Correspondence to: I. Willis (iain.willis@ jbarisk.com)
}

Received: 16 February 2016 - Published in Nat. Hazards Earth Syst. Sci. Discuss.: 22 February 2016

Revised: 23 May 2016 - Accepted: 24 May 2016 - Published: 15 June 2016

\begin{abstract}
In the field of disaster risk reduction (DRR), there exists a proliferation of research into different ways to measure, represent, and ultimately quantify a population's differential social vulnerability to natural hazards. Empirical decisions such as the choice of source data, variable selection, and weighting methodology can lead to large differences in the classification and understanding of the "at risk" population. This study demonstrates how three different quantitative methodologies (based on Cutter et al., 2003; Rygel et al., 2006; Willis et al., 2010) applied to the same England and Wales 2011 census data variables in the geographical setting of the 2013/2014 floods of the River Parrett catchment, UK, lead to notable differences in vulnerability classification. Both the quantification of multivariate census data and resultant spatial patterns of vulnerability are shown to be highly sensitive to the weighting techniques employed in each method. The findings of such research highlight the complexity of quantifying social vulnerability to natural hazards as well as the large uncertainty around communicating such findings to stakeholders in flood risk management and DRR practitioners.
\end{abstract}

\section{Introduction}

The impacts of a natural hazard event upon a population vary considerably depending on the socioeconomic attributes of the people exposed to the hazard (O'Keefe et al., 1976; Yoon, 2012; Zakour and Gillespie, 2013). This concept can be termed social vulnerability, but the exact definition of this term, and other associated concepts such as resilience and adaptive capacity, is contested within the literature (Brooks, 2003; Fuchs, 2009; Kuhlicke et al., 2011). These disparate views on social vulnerability are a consequence of models/frameworks to explain the relationship between hazard, risk, and vulnerability emanating from distinct schools of thought. Birkmann et al. (2013) list these schools as including political ecology, social ecology, vulnerability, disaster risk assessment, and climate change system adaption. The definition of social vulnerability from political ecology is used here: "the characteristics of a person or group and their situation that influences their capacity to anticipate, cope with, resist, and recover from the impact of a hazardous event" (Wisner et al., 2004, p. 11).

An individual's level of social vulnerability is multifaceted and determined by a number of spatially and temporally distant political, economic, and social "root causes" (Birkmann et al., 2013; Watts and Bohle, 1993). These processes ultimately manifest at a local scale into a range of "unsafe conditions": e.g. living in dangerous locations, low income (see the Pressure and Release Model (PAR) developed by Wisner et al., 2004). Natural hazards cannot be prevented, but the impact of natural hazards can be lowered by reducing the social vulnerability of the exposed population (Zakour and Gillespie, 2013). Therefore, there is great value in quantifying and spatially mapping "unsafe conditions", i.e. a population's social vulnerability, to target mitigation and adaptation strategies at the areas that are both exposed and with high social vulnerability, i.e. the most at risk populations (Nelson et al., 2015; Rygel et al., 2006; Yoon, 2012). An often used method to quantify social vulnerability 
is based on the "hazards-of-place" model (Cutter et al., 2006) which is a conceptual understanding of how unsafe conditions interact at the local scale to produce a place vulnerability. Cutter et al. (2003) subsequently developed a quantitative methodology to identify and classify social vulnerability using census data, which became trademarked, known as the Social Vulnerability Index $\left(\mathrm{SoVI}^{\circledR}\right)$. Whilst there are strengths and weaknesses of using such indicator- and indexbased methodologies to assess social vulnerability, as detailed by Kuhlicke et al. (2011), the approach is used extensively, e.g. by Myers et al. (2008), Reid et al. (2009), Tapsell et al. (2002), Rygel et al. (2006), Willis et al. (2010), and Tomlinson et al. (2011).

Despite a general consensus in social science about some of the main factors influencing an individual's social vulnerability, e.g. age, income, health, education level (Adger et al., 2004; Cutter et al., 2003, 2006; Wisner et al., 2004). However, there has been no agreement on a set of social vulnerability indicators for environmental hazards to use within an index (Cutter et al., 2003; Yoon, 2012). The data to include are constrained by the indicators relevance to the particular hazard(s) being assessed, and whether data are available and current (census data are often the primary data source). As a result, the number and type of vulnerability indicators used within the construction of social vulnerability indices varies considerably depending on the type of analysis and methods used (Nelson et al., 2015).

Once the relevant vulnerability indicators have been selected to construct an index, they are combined into a single metric. However, Yoon (2012, p. 824) states that "there is still no consensus ... on the quantitative methodology best suited to assess social vulnerability". Within the literature, the predominant method used is a multivariate factorial method, in the form of principal component analysis (PCA) using census data (e.g. Rygel et al., 2006; Boruff et al., 2005; Cutter et al., 2003; Clark et al., 1998). Willis et al. (2010) use another method which utilised a commercial geodemographic (Experian Mosaic Italy) classification as the main data source and Gini coefficients to weight the vulnerability variables.

Yoon (2012) analysed the difference between a deductive and inductive approach when creating a vulnerability index, but there has been no further research into comparing different vulnerability methodologies. Therefore, there is limited information on whether, all being equal, the different vulnerability methodologies classify the same people as highly vulnerable. The aim of this paper is to compare the social vulnerability indices produced when using three published methodologies: a method based on Cutter et al. (2003), a method using Pareto ranking based on Rygel et al. (2006), and a method with Gini coefficient weighting based on Willis et al. (2010). The area of the River Parrett catchment, UK, which was severely flooded in the winter of 2013/2014, will be used as a case study. If these approaches identify different populations as vulnerable, it raises a number of questions about how the "at risk" population is defined. This paper will firstly review the chosen vulnerability index methodologies and describe the case study area. Secondly, the method used to compare the social vulnerability indices will be detailed. Finally, the results will be presented and discussed.

\section{Quantitative approaches to measure social vulnerability}

Quantitative social vulnerability methodologies are predominantly based around the concept of indicators. That is to say, they are based on the a priori understanding that a given statistical variable, typically being socioeconomic or ethnographic, is highly correlated with an individual or group of people's inherent vulnerability before, during, or after a given natural disaster. The qualitative research of such disaster experience includes historic evidence from various hurricanes, floods, earthquakes, and famine (McMaster and Johnson, 1987; Lew and Wetli, 1996; Johnson and Zeigler, 1986; Chakraborty et al., 2005; Dow and Cutter, 2002; Burton et al., 1993; Morrow, 1999; Dwyer et al., 2004). Such findings have subsequently guided the principles of quantitative researchers seeking to identify and model the most vulnerable population groups from the impact of future catastrophes. Aside from the indicator-based approaches examined in this paper (Cutter et al., 2003; Rygel et al., 2006; Willis et al., 2010), it is important to note the influence of the wider global initiatives aimed at creating greater community resilience for disaster mitigation. The UN's Hyogo Framework (20052015) provided the contextual setting for much of this effort in the last 10 years and identified core aims focused on tools to help in disaster risk reduction (DRR), including Priority Action 2, specifically aimed to "identify, assess and monitor disaster risks and enhance early warning" (UNISDR, 2005) with specific reference to the use and application of vulnerability indicators. Though the concept of indicator-based approaches has historically been used to underpin economic theory (Hartmuth, 1998; Reich, 1983) or environmental indicators in the 1970s (Werner and Smith, 1977; Füssel, 2007), the methodologies discussed in this research are aligned with the more recent sustainable development concept of indicators (Birkmann, 2006).

Indicator-based approaches can provide the practical means for practitioners in DRR to identify vulnerable population groups or communities to the risk(s) of a given peril. Similarly, these methodologies are not restricted in their spatial scale or scope, whether being a global "hotspots" assessment of multiple natural hazard risk (Dilley, 2005) or single peril, census-based index examining flood vulnerability, as developed by Lindley et al. (2011). It is important to be mindful that indicator approaches are not without their fundamental limitations. The "definitions and drivers of vulnerability and indicators to measure them vary between industrialised and less-industrialised nations, especially where development pressures are inextricably linked to risk and vulner- 
Table 1. Summary of the three social vulnerability methods applied within this paper.

\begin{tabular}{|c|c|c|c|}
\hline & Cutter et al. (2003) & Rygel et al. (2006) & Willis et al. (2010) \\
\hline Hazard & General environmental hazards & Hurricane storm surges & Volcanic eruption \\
\hline Study area & USA & $\begin{array}{l}\text { The Hampton Roads, } \\
\text { Virginia, USA }\end{array}$ & $\begin{array}{l}\text { Mount Vesuvius, Naples, } \\
\text { Italy }\end{array}$ \\
\hline Data source & 1990 US census & 2000 US census & Experian Mosaic Italy \\
\hline Spatial unit & County & Census unit & Census unit \\
\hline Number of indictors & 42 & 57 & 7 \\
\hline Indicator format & Percentages, per capita, density functions & $\begin{array}{l}\text { Percentages, areal } \\
\text { densities }\end{array}$ & Propensity index score \\
\hline PCA factors & $\begin{array}{l}11 \text { - explained } 76.4 \% \text { of variance (used } \\
\text { Varimax rotation) }\end{array}$ & $\begin{array}{l}3 \text { - explained } 50.83 \% \text { of } \\
\text { variance (used Varimax } \\
\text { orthogonal) }\end{array}$ & Did not directly use PCA \\
\hline $\begin{array}{l}\text { Vulnerability } \\
\text { dimensions }\end{array}$ & $\begin{array}{l}\text { Personal wealth, age, density of the built } \\
\text { environment, single-sector economic } \\
\text { dependence, housing stock and tenancy, } \\
\text { race (African American, Asian) ethnicity } \\
\text { (Hispanic, Native American), occupation, } \\
\text { infrastructure dependence }\end{array}$ & $\begin{array}{l}\text { Poverty, immigrants, old } \\
\text { age/disabilities }\end{array}$ & $\begin{array}{l}\text { Evacuation, financial } \\
\text { recovery, building } \\
\text { vulnerability, access to } \\
\text { resources }\end{array}$ \\
\hline $\begin{array}{l}\text { Method used to } \\
\text { combine indicators }\end{array}$ & Addition of extraction scores & $\begin{array}{l}\text { Pareto ranking of factor } \\
\text { scores }\end{array}$ & $\begin{array}{l}\text { Addition and averaging } \\
\text { of weighted (using Gini } \\
\text { coefficients) index score }\end{array}$ \\
\hline
\end{tabular}

ability from local to global scales" (Birkmann, 2006, 304305). Applying the concepts of social vulnerability, as evidenced by indicators in one contextual setting, does not mean that the same concepts can be applied or appropriate in another geography or spatial scale. Vulnerability is a dynamic notion, and thus it is important to assess any indicator-based approach within the political, environmental, and socioeconomic landscape that it is being applied.

In this study, the examination of indicator-based approaches has been limited to three multivariate approaches utilising census data (Cutter et al., 2003; Rygel et al., 2006; Willis et al., 2010). These methodologies all make use of PCA but with different intent and application. PCA is used to "reduce the dimensionality of a data set consisting of a large number of interrelated variables, while retaining as much as possible of the variation present in the data set" (Jolliffe, 2002, p. 1). PCA is a useful tool when creating composite vulnerability indices, as a number of vulnerability indicators are used which are often correlated to various degrees. By using PCA, it is intended that factors or components that inherently capture social vulnerability are created. Whilst Willis et al. (2010) did not make explicit use of PCA extraction scores in their quantitative assessment of social vulnerability, multivariate analysis was used in the screening and assessment of variables; hence its inclusion in this comparison.
Cutter et al. (2003) first used the SoVI approach to assess social vulnerability to general environmental hazards using 1990 US census data, whereby 42 initial variables were reduced to 11 components using factor analysis (see Table 1 for further information). On this basis, the 11 factors identified in PCA accounted for $76.4 \%$ of the variance within the data. These components were subsequently used to derive an overall SoVI. The principle underlying the methodology includes a binary assumption of the trend of specific vulnerabilityrelated census variables. Variables included in the initial assessment were assumed to have a positive or negative cardinality in their relationship to vulnerability. For example, "non-white ethnicity" was considered to increase an individual's social vulnerability on the basis of historical studies of disaster experience (Pulido, 2000; Bolin et al., 1998). Conversely, indicators relating to "wealth" are seen as negative factors, reducing the relative social vulnerability score. Following this process of initial variable selection, PCA is then undertaken to analyse the variables. The method used by Cutter et al. (2003) recommends the preservation of cardinality between vectors; hence, any variables not correlated with the principal components of vulnerability are recommended to be removed and any scores negatively correlated to vulnerability are inverted. Cutter et al. (2003) recommend that a varimax orthogonal rotation be undertaken to reduce the loading on the first component, as well as provide more independence 
among factors. Extraction scores are then output for each factor in the data and summed against the initial variables in an additive model to produce a composite SoVI score.

Rygel et al. (2006) used a modified approach to the SoVI in their assessment of areas vulnerable to hurricane storm surge (Table 1). Following PCA and subsequent varimax rotation of the variables, it is proposed that Pareto ranking is applied to the PCA extraction scores (see Rygel et al. (2006) for a fuller explanation of the theory of Pareto ranking). The basis of applying a Pareto distribution across the vulnerability scores is to remove the requirement of individually weighted scores and, thus, overcome concerns about systematic bias. Each component score is then ranked on the basis of a user defined interval (19 in the original method) and an overall ranking is determined.

Willis et al. (2010) analysed Italian census areas around Mount Vesuvius using Mosaic Italy 2007 geodemographic index scores (Table 1). Instead of using PCA extraction scores, it was proposed that an additive model was applied, whereby social vulnerability variables were weighted according to their economic Gini coefficient value to provide a composite score. The concept of this approach being that the Gini coefficient provides a precise measure of variable discrimination and therefore an appropriate weighting tool to assign some vulnerability variables with higher loadings than others.

\section{The River Parrett catchment}

For the purposes of comparing the alternative methodologies, it was decided that a relevant geographical setting be used to apply the vulnerability scores within a pertinent context. By doing so, it was proposed that meaningful assessment could be undertaken of the results within a realistic natural hazard setting. The Parrett catchment, in Dorset/Somerset, UK, was chosen as the case study area for this research (Fig. 1). The Environment Agency (2009) report that the Parrett catchment is approximately $1700 \mathrm{~km}^{2}$ and, along with the River Parrett, includes the Isle, Tone, Yeo, and Cary rivers which flow in a northerly and westerly direction into an extensive lowland floodplain, before flowing out into the Bristol Channel via the Parrett Estuary. The catchment contains approximately 300000 people; however, the catchment is predominately rural (only $4 \%$ is considered urban), with three main urban centres (Yeovil, Taunton, and Bridgwater). The Environment Agency (2009) estimate that 3300 properties are potentially exposed to a $1 \%$ annual probability flood event within the catchment, with this possibly rising to over 6600 properties in the future due to the impacts of climate change. There is evidence that this rise is likely to occur as the flooding in England and Wales in 2013/2014 is thought to be linked to human-induced climate change (Schaller et al., 2016). Furthermore, Bridgwater was used as a case study area by Thaler and Levin-Keitel (2016), who identified the area as having

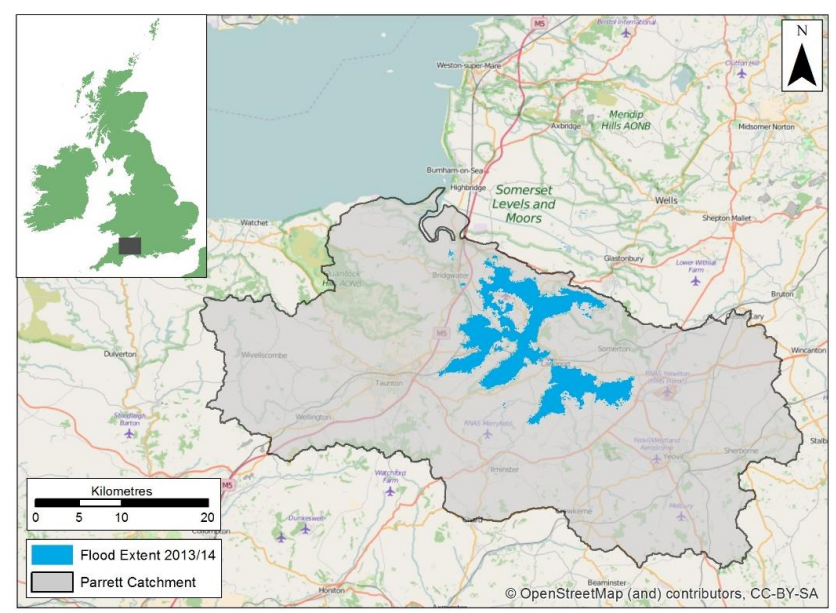

Figure 1. The location of the Parrett catchment, within the Somerset Levels area of south-western UK. The extent of the flooding in 2013/2014 is also shown.

a low capacity to engage in flood risk management due to the lack of socioeconomic structures (i.e. cultural capital, income, and interest).

The UK experienced an unprecedented level of rainfall during the winter of 2013/2014, resulting in prolonged flooding in England and Wales, which is estimated as 10465 flooded properties, and caused a total of GBP 1.3 billion in economic damages (Chatterton et al., 2016). The rainfall flooded a $65 \mathrm{~km}^{2}$ area of the Somerset Levels area of the River Parrett catchment (Environment Agency, 2015). Approximately 600 properties were flooded during this period, leaving a number of towns and villages cut off due to the high floodwaters. Flood waters persisted until March 2014 and the damage witnessed raised a national debate about the lack of dredging in the rivers throughout the Parrett catchment (Coghlan, 2014; Environment Agency, 2015). This political pressure resulted in ministerial intervention and the subsequent production of "The Somerset Levels and Moors Flood Action Plan", a 20-year scheme to mitigate future flood potential and increase the level of funding for flood management in the region (Somerset County Council, 2014).

Alongside the physical damage of the Somerset Levels flooding, there has been limited consideration of the social vulnerability of those communities affected. Within the River Parrett catchment area there are a range of socioeconomic profiles, and while many of the most deprived communities (those located in urbanised areas such as Yeovil, Taunton, and Bridgewater) were not adversely impacted, flood risk potential remains high. In the wider context of flood risk management, England and Knox $(2015$, p. 7) show that in England "levels of planned expenditure in flood risk management to 2021 do not appear to align with areas of significant flood disadvantage, or with wider deprivation"; i.e. the social vulnerability of the population potentially impacted by 
flooding currently has no bearing on spending decisions. In this instance, vulnerability to flooding used by England and Knox (2015) was derived using a method based on Cutter el al. (2003) by Lindley et al. (2011).

Given the prevalence of flood risk, range of socioeconomic characteristics, and combination of urban and rural populations within the Parrett catchment, the area was seen as an ideal case study for this research. To help confine the research to the flood risk case study area, a GIS spatial extent, as seen in Fig. 1, was delineated for the River Parrett catchment area and used as the bounding area to select the England and Wales census output areas within the catchment. Similarly, a flood footprint relating to the 2013/2014 event was digitised as a GIS layer based on the maximum extent identified by the Environment Agency (2014). This extent provided the basis of comparison results highlighted in Fig. 7 and Table 6.

\section{A standardised methodology to compare quantitative approaches}

The principle aim of this study was to devise a methodology that could allow the different quantitative social vulnerability methods (outlined earlier in this paper) to be compared in a consistent manner. For this purpose, it was necessary to devise a repeatable process, whereby only the weighting of the variables would be changed to recognise each different methodology.

\section{Selection of vulnerability indicators}

Data for this study were taken from the 2011 Area Classification for Output Areas, a joint venture between the Office of National Statistics (ONS) and University College London to help disseminate and inform researchers about the 2011 Output Area Classification (OAC2011). The OAC2011 is a neighbourhood classification based on the most recent UK census, conducted in March 2011. This study has made use of the UK output area spatial boundaries (in ESRI shapefile format) as well as census variable data (at output area level) used to construct the OAC2011 neighbourhood classification available from http://geogale.github.io/2011OAC/.

The England and Wales census data were used in this study which comprises of 232296 output areas (ONS 2011). It is important to note that not all data collected from the census are used in the creation of the OAC2011. To devise the neighbourhood classification, a process of variable selection was used to help determine data inter-dependencies, correlations, and other factors that may affect the clustering process (Vickers et al., 2005). Of the 59 census variables (including derived statistics) used to create the OAC2011, it was determined that only seven specific data variables would be suitable for inclusion in the social vulnerability classification comparison (Table 2).
There were two main reasons for the seven initial indicators shown in Table 2. Firstly, as the focus of the study was to determine the difference that alternative weighting mechanisms may have on vulnerability scores, using fewer indicators made it easier to infer the influence of each methodology being reviewed. Secondly, not all census variables were eligible for inclusion in this study given that the focus was on determining factors that impact a neighbourhood's social vulnerability during extreme flooding. Whilst not exhaustive, Table 2 provides example studies of where age, ethnicity, and disability have been shown to impact social vulnerability to support the selection of indicators within this study. Table 3 shows the correlation between the selected vulnerability indictors, with "persons aged 65 to 89" and "individuals dayto-day activities limited a lot or a little" (K005 and K035) showing the strongest relationship (0.687). Table 3 demonstrates that none of the variables show particularly high degrees of correlation, and therefore none of the indicators were removed from the analysis on this basis.

\section{Data standardisation}

The data from the England and Wales census are not in a standardised format or description. For example, age group data (K001 and K005) were initially provided as numerical counts within the output area. These values had to then be converted to a percentage with respect to the overall population recorded within a given output area. Alternatively, population density (K007) was recorded as a measure of people per hectare and disability (K045) noted according to the standardised illness ratio. Whilst these data formats are relevant for their respective measures of a phenomenon, they would not have been suitable for multivariate analysis, correlation tests or weighting variables against one another. For this purpose, it was necessary to firstly standardise the data into a homogenous format. There are commonly two methods employed to standardise data, including $\mathrm{Z}$ scores or Range standardisation (Wallace and Denham, 1996). In this case, the Range standardisation method was applied as it was also used in the construction of the OAC2011 and was therefore determined to be the most relevant to this research (Vickers et al., 2005). The Range standardisation is shown in Eq. (1), whereby the standardised observation $\left(x_{n}\right)$ is calculated as a ratio from the maximum and minimum observations for a given variable. This leads to all observation values being classified between 0 AND 1.

$x_{n}=\frac{x-x_{\min }}{x_{\max }-x_{\min }}$

\section{Exploratory principal component analysis}

To help assess the cardinality of the data variables as well as their inter-dependency and variance, PCA was undertaken 
Table 2. 2011 UK census data variables used as the indicators to assess social vulnerability to flooding.

\begin{tabular}{llll}
\hline Census code & Indicator description & $\begin{array}{c}\text { Effect on social } \\
\text { vulnerability }\end{array}$ & Supporting literature \\
\hline K001 & Persons aged 0 to 4 & Negative & $\begin{array}{l}\text { McMaster and Johnson Jr. (1987); } \\
\text { Lew and Wetli (1996) }\end{array}$ \\
\hline K005 & Persons aged 65 to 89 & Negative & $\begin{array}{l}\text { McMaster and Johnson Jr. (1987); } \\
\text { Lew and Wetli (1996) }\end{array}$ \\
\hline K007 & Number of persons per hectare & Negative & $\begin{array}{l}\text { Johnson and Zeigler (1986); } \\
\text { Chakraborty et al. (2005); } \\
\text { Dow and Cutter (2002) }\end{array}$ \\
\hline K023 & $\begin{array}{l}\text { Main language is not English and cannot } \\
\text { speak English well or at all }\end{array}$ & Negative & $\begin{array}{l}\text { Pulido (2000); Elliott and Pais } \\
\text { (2006) }\end{array}$ \\
\hline K035 & $\begin{array}{l}\text { Households who are social renting } \\
\text { Individuals day-to-day activities limited a } \\
\text { lot or a little (standardised illness ratio) }\end{array}$ & Negative & $\begin{array}{l}\text { Morrow (1999); Dwyer et al. } \\
\text { (2004) }\end{array}$ \\
\hline K045 & $\begin{array}{l}\text { Persons aged between 16 and 74 who are } \\
\text { unemployed }\end{array}$ & Negative & Burton et al. (1993) \\
\hline
\end{tabular}

Table 3. Correlation between input vulnerability indicators.

\begin{tabular}{rrrrrrr}
\hline & K001 & K005 & K007 & K023 & K033 & K035 \\
\hline K005 & -0.501 & & & & & \\
K007 & 0.282 & -0.62 & & & & \\
K023 & 0.644 & -0.518 & 0.617 & & & \\
K033 & -0.225 & -0.565 & 0.599 & 0.201 & & \\
K035 & -0.044 & 0.687 & -0.162 & -0.133 & -0.499 & \\
K045 & 0.685 & -0.364 & 0.591 & 0.586 & -0.027 & 0.389 \\
\hline
\end{tabular}

on the standardised census data. An initial PCA showed that three components accounted for $91 \%$ of the overall variance in the data, with the first component accounting for $48 \%$. Further analysis of this component showed that the variables "population density" (K007), "non-English speaking" (K023) and "unemployment" (K045) were highly correlated and had the largest component loadings. Conversely, the variables "age 65-89" (K005) and "standardised illness ratio" (K035) showed negative loadings for the same component. This pattern of correlation among variables can be seen further in Fig. 2 whereby the cardinality of vectors are positively aligned for K007, K023, K001, and K045. Conversely, K005 showed strong negative correlation with all variables apart from K035.

\section{Assess cardinality of vectors}

The method used by Cutter et al. (2003) proposed that following analysis, only vectors with the same cardinality should be retained for inclusion in the vulnerability index. This is based around the concept that each of the variables

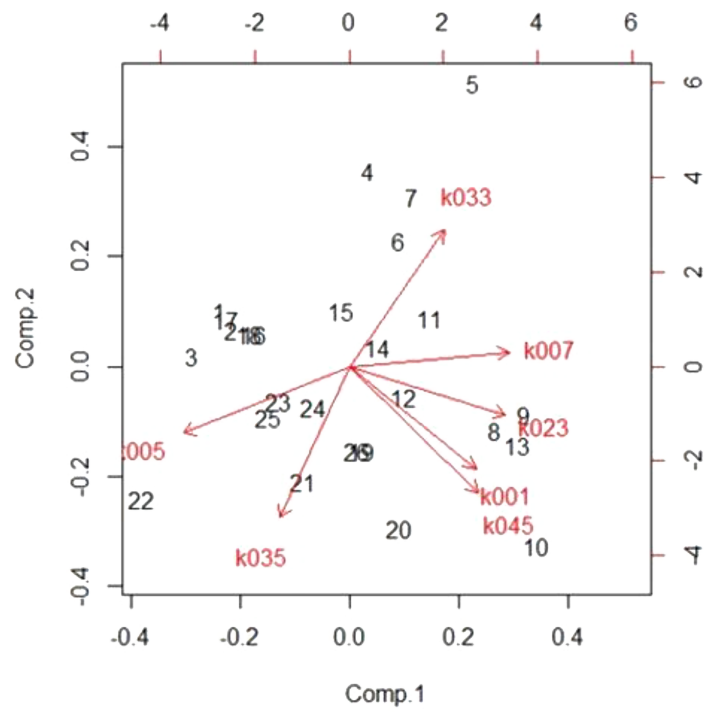

Figure 2. Biplot of component vectors.

remaining is correlated with vulnerability and, therefore, an index can be produced by summing these variables with the component score. It should be noted that Cutter's approach states that where a variable is understood to reduce vulnerability due to having a positive effect (such as a household's wealth/income), the variable should be inverted to become a negative score.

Although Rygel et al. (2006) and Willis et al. (2010) did not espouse reducing variables on the basis of PCA cardinality, it was necessary to remove variables K005 and K033 from further inclusion to ensure a consistent methodology 


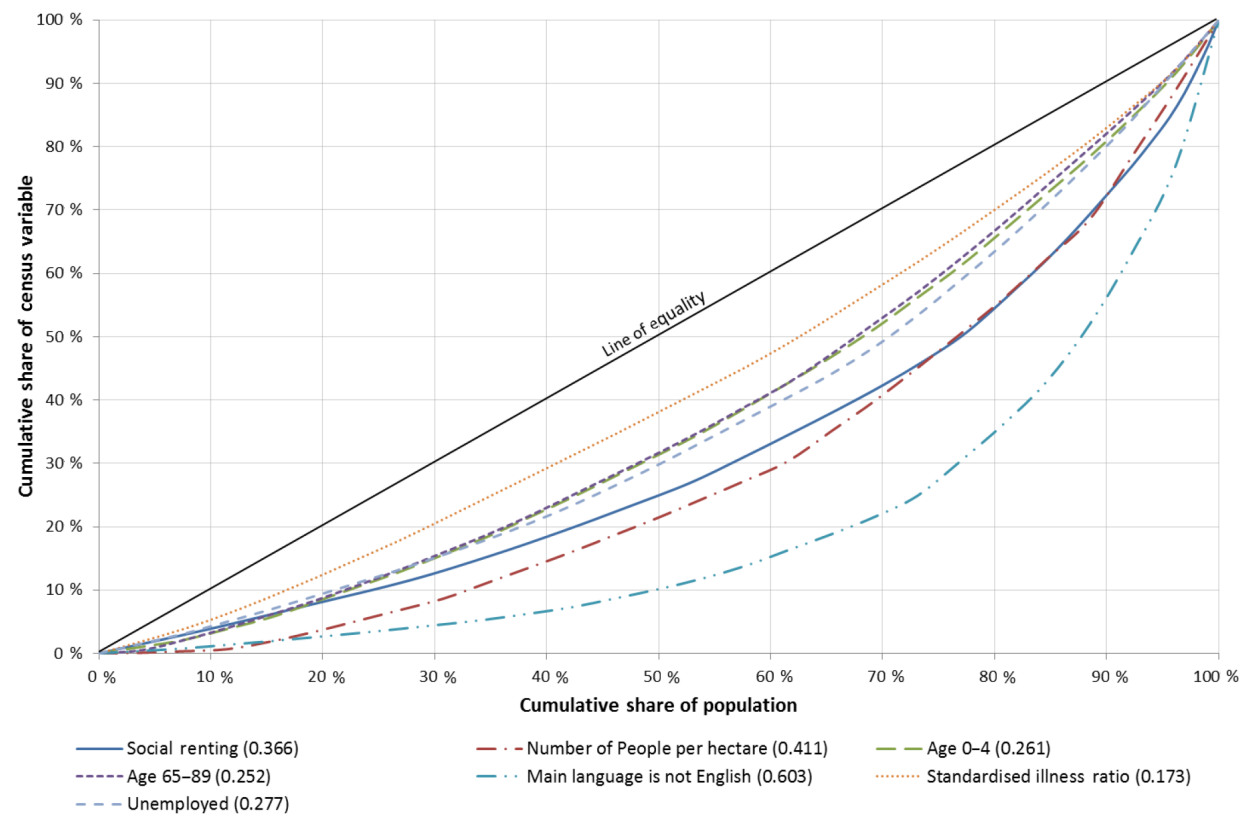

Figure 3. Lorenz curves of Output Area Classification (OAC) selected to assess social vulnerability to flooding. Gini coefficient is shown within the graph legend.

was maintained. As the comparison methodologies outlined in Cutter et al. (2003) and Rygel et al. (2006) made use of rotated component scores as an input to the vulnerability assessment, a similar step would be required in this research to maintain continuity of the methods being compared. In accordance with the prescriptive methodologies outlined in these applications of multivariate analysis, the remaining five variables were subsequently rotated using a varimax rotation, and the component scores extracted for each output area. The extracted score became a new input variable (referred to hereafter as "PCA vulnerability score") and was used in the creation of the vulnerability indices outlined in the results section.

\section{Gini coefficients}

Figure 3 provides a summary of the Lorenz curves for each of the variables. Lorenz curves provide a graphical illustration of the Gini Coefficient and thus show the cumulative distribution of a variable within a population (Gastwirth, 1972). The greater the area between the curve and the "line of equality" represents how skewed or discriminatory a variable is within a given population.

Figure 3 highlights how UK census variables, such as "main language is not English" (K023), are disproportionately distributed among the OAC classification groups. In comparison, "standardised illness ratio" (K035) is much less skewed among these profiles. This was further highlighted by the corresponding Gini coefficient values: 0.603 and 0.173 respectively for the variables. This was calculated using a generalised method (Bellù and Liberati, 2006) whereby values closer to 1 represent greater inequality than values closer to 0 .

\section{Apply weighting}

Though the alternative methodologies shared many similarities, they also had distinct differences in their selection, weighting, and summation of the input variables. The application of each of methodology to the standardised census data is summarised in Table 4.

In terms of input variables, Cutter's SoVi Recipe recommends an additive approach, whereby the individual census variables are added together along with the PCA extraction score created during rotation of the variables (Cutter et al., 2008). Willis et al. (2010) have a similar approach in summing variables but do not use the additional extraction scores. Conversely, Rygel et al. (2006) do not use any of the input census variables and instead use only the vulnerability extraction score to provide a summary of the output area. Rygel et al. (2006) recommend applying a Pareto ranking to the extraction scores, which involves placing observations into discrete "blocks" or ranges. Depending on how many components are input, the data can be ranked on multiple variables. The final step in the process is to sum the ranks and provide an overall weighting. The intention of doing this is to reduce the skew effect that one variable may have on the overall result. The procedure of Pareto ranking is highly subjective in the choice of how many ranks or intervals are created for the given distribution of observations. Based on the proportion 
Table 4. Summary of how the social vulnerability index is constructed using the three different methods.

\begin{tabular}{llll}
\hline & Cutter et al. (2003) & Rygel et al. (2006) & Willis et al. (2010) \\
\hline Variables & $\begin{array}{l}\text { K001 + K007 + K023 + K045 } \\
\text { + PCA vulnerability score }\end{array}$ & PCA vulnerability score & K001 + K007 + K023 + K045 \\
\hline Process & Additive & $\begin{array}{l}\text { Pareto ranking } \\
(100 \text { intervals })\end{array}$ & Additive \\
& & Index $\left(X_{i} / X_{\text {mean }} \times 100\right)$ & Index $\left(X_{i} / X_{\text {mean }} \times 100\right)$ \\
\hline Output & Index $\left(X_{i} / X_{\text {mean }} \times 100\right)$ & & \\
\hline
\end{tabular}

of intervals that Rygel et al. (2006) used in their study of US counties, it was decided that 100 intervals would provide an approximate correlation for the output areas based on the PCA vulnerability score.

The final methodological step was to provide a normalised output from each technique to compare the results in a systematic manner. For this purpose, a propensity index was used. A propensity index is commonly used in geodemographics to convey relative variable scores and reduce any apparent bias between variable distributions. Equation (2) below summarises how the index score for a variable $\left(x_{i}\right)$ is calculated from a ratio of the observation value $(x)$ from the variable mean average $(\bar{x})$ multiplied by 100 .

$x_{i}=\frac{x}{\bar{x}} \times 100$

\section{Results}

\section{Distribution of social vulnerability scores}

Figure 4 shows the correlation between the social vulnerability index scores derived from each of the three methods. The social vulnerability scores from Cutter et al. (2003) and Willis et al. (2010) show a relationship close to linear with a strong correlation evident $\left(R^{2}=0.8975\right)$. Comparison of the Cutter et al. (2003) and Rygel et al. (2006) scores again show an almost linear relationship but the data show less correlation $\left(R^{2}=0.6341\right)$. The relationship between the Willis et al. (2010) and Rygel et al. (2006) results show a much weaker correlation $\left(R^{2}=0.4405\right)$. The Willis et al. (2010) scores show that the method produces a more extreme classification of scores than the Rygel et al. (2006) scores, shown by the flattening of the trend line. Figure 5 highlights the distribution of vulnerability scores across the output areas for all methodologies for the Parrett catchment. Whilst the graph shows a correlation between the Gini coefficient approach (Willis et al., 2010) and Cutter's method (Cutter et al., 2003), Rygel's Pareto ranking method (2006) displays a greater variation in the classification of the same output areas; the choice of 100 rank intervals used in the method appears paramount to the relative distribution of these scores.
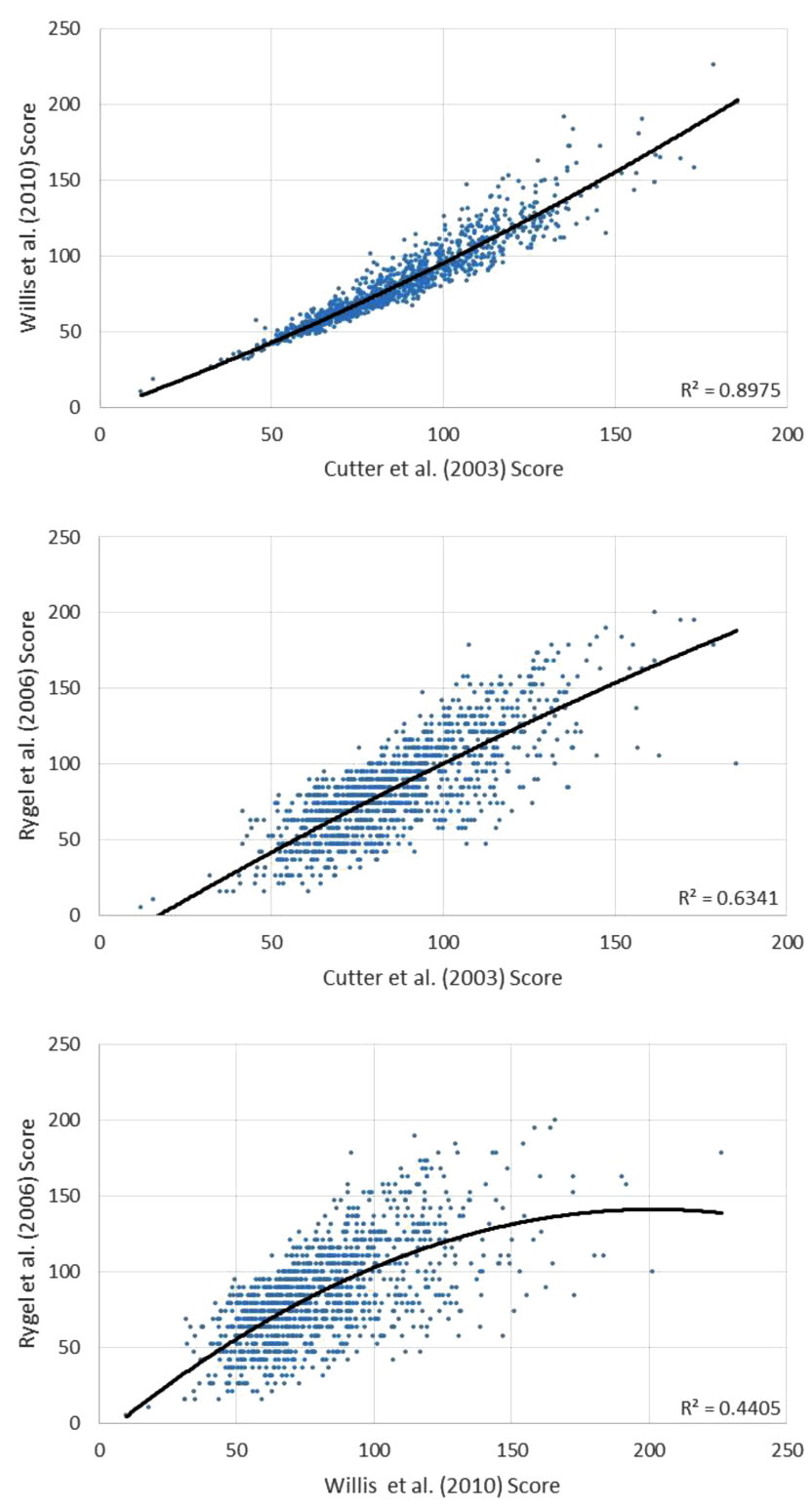

Figure 4. Correlation of social vulnerability index scores for the Parrett Catchment. Trend lines are polynomial. 
Table 5. Comparison of mean and standard deviations of the social vulnerability index scores by OAC 2011 classification within the Parrett catchment. The mean and standard deviation of the England and Wales (E \& W) is shown for comparison.

\begin{tabular}{|c|c|c|c|c|c|}
\hline & $\begin{array}{l}\text { OAC } 2011 \text { supergroup } \\
\text { classification }\end{array}$ & $\begin{array}{l}\text { Number of } \\
\text { output areas }\end{array}$ & $\begin{array}{r}\text { Cutter et al. (2003) } \\
\text { mean score }\end{array}$ & $\begin{array}{r}\text { Willis et al. (2010) } \\
\text { mean score }\end{array}$ & $\begin{array}{r}\text { Rygel et al. (2006) } \\
\text { mean score }\end{array}$ \\
\hline \multirow{9}{*}{ 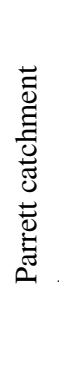 } & Constrained city dwellers & 78 & 124.8 & 123.6 & 138.3 \\
\hline & Cosmopolitans & 12 & 87.3 & 94.5 & 95.6 \\
\hline & Hard-pressed living & 258 & 102.4 & 96.9 & 105.4 \\
\hline & Multicultural metropolitans & 5 & 125.6 & 148.2 & 102.1 \\
\hline & Rural residents & 388 & 72.5 & 63.7 & 70.0 \\
\hline & Suburbanites & 154 & 73.8 & 66.5 & 68.2 \\
\hline & Urbanites & 223 & 91.8 & 91.5 & 82.4 \\
\hline & Total & 1118 & 87.5 & 82.2 & 85.6 \\
\hline & $\mathrm{SD}$ & - & 23.3 & 27.3 & 33.1 \\
\hline 3 & Total & 232296 & 100 & 100 & 100 \\
\hline$\infty$ & SD & - & 32.5 & 42.6 & 42.3 \\
\hline
\end{tabular}

Table 6. Analysis of the areas impacted by the 2013/2014 flooding of the Somerset levels.

\begin{tabular}{lcrrr}
\hline $\begin{array}{l}\text { OAC 2011 supergroup } \\
\text { classification }\end{array}$ & $\begin{array}{r}\text { Number of } \\
\text { output areas }\end{array}$ & $\begin{array}{r}\text { Cutter et al. (2003) } \\
\text { mean score }\end{array}$ & $\begin{array}{r}\text { Willis et al. (2010) } \\
\text { mean score }\end{array}$ & $\begin{array}{r}\text { Rygel et al. (2006) } \\
\text { mean score }\end{array}$ \\
\hline Hard-pressed living & 2 & 102.1 & 86.3 & 110.5 \\
Rural residents & 67 & 71.9 & 63.9 & 67.0 \\
Suburbanites & 1 & 81.6 & 74.9 & 100.0 \\
Urbanites & 3 & 110.3 & 119.5 & 124.6 \\
\hline Total & 73 & 74.5 & 66.9 & 71.0 \\
SD & - & 15.4 & 18.2 & 24.1 \\
\hline
\end{tabular}

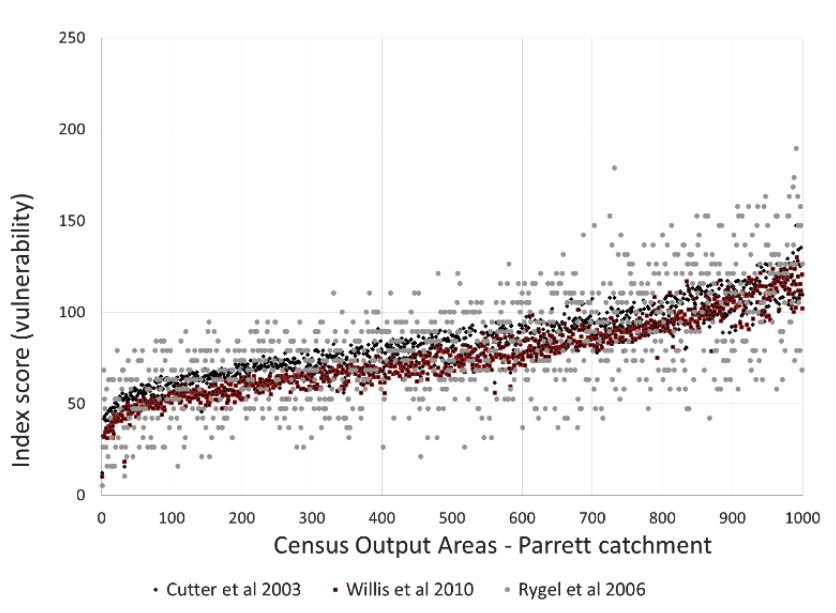

Figure 5. Output area comparison of social vulnerability index scores for the Parrett catchment.

This point is further shown in the correlation plots of Fig. 4 by the "stepped" pattern of the Rygel et al. (2006) data and in Table 5 with the standard deviation for the Rygel et al. (2006) approach being 33.1 in comparison to the Willis et al. (2010) method (27.3) and Cutter et al. (2003) approach (23.3) for the Parrett catchment. Interestingly, this relationship is not the same when considering all of the England and Wales output areas, whereby the Willis et al. (2010) method resulted in the highest standard deviation (42.6). This last point appears due to the loading factor the Willis et al. (2010) method had on vulnerability scores that are greater than 100, thus leading to outlier scores. The Cutter et al. (2003) method showed the lowest standard deviation at all spatial scales along with the highest mean score (87.5) of vulnerability in the Parrett catchment, when compared to the other techniques.

In terms of the spatial distribution of scores, the three comparative methodologies show a high degree of correlation with regard to their urban-rural pattern of vulnerability scoring (Table 5). Vulnerability index scores greater than 100 were largely constrained to the centres of greatest population density, most notably the large Somerset towns of Taunton, Bridgwater, and Yeovil. Table 5 shows that the highest average social vulnerability scores across the three methods are found in output areas classed by the OAC2011 classification as "constrained city dwellers" and "multicultural metropolitans". Similarly, and despite subtle differences in the magnitude of scoring, spatial correlation was noted to be closer between Cutter et al. (2003) and Willis et al. (2010) in comparison to Rygel et al. (2006). 

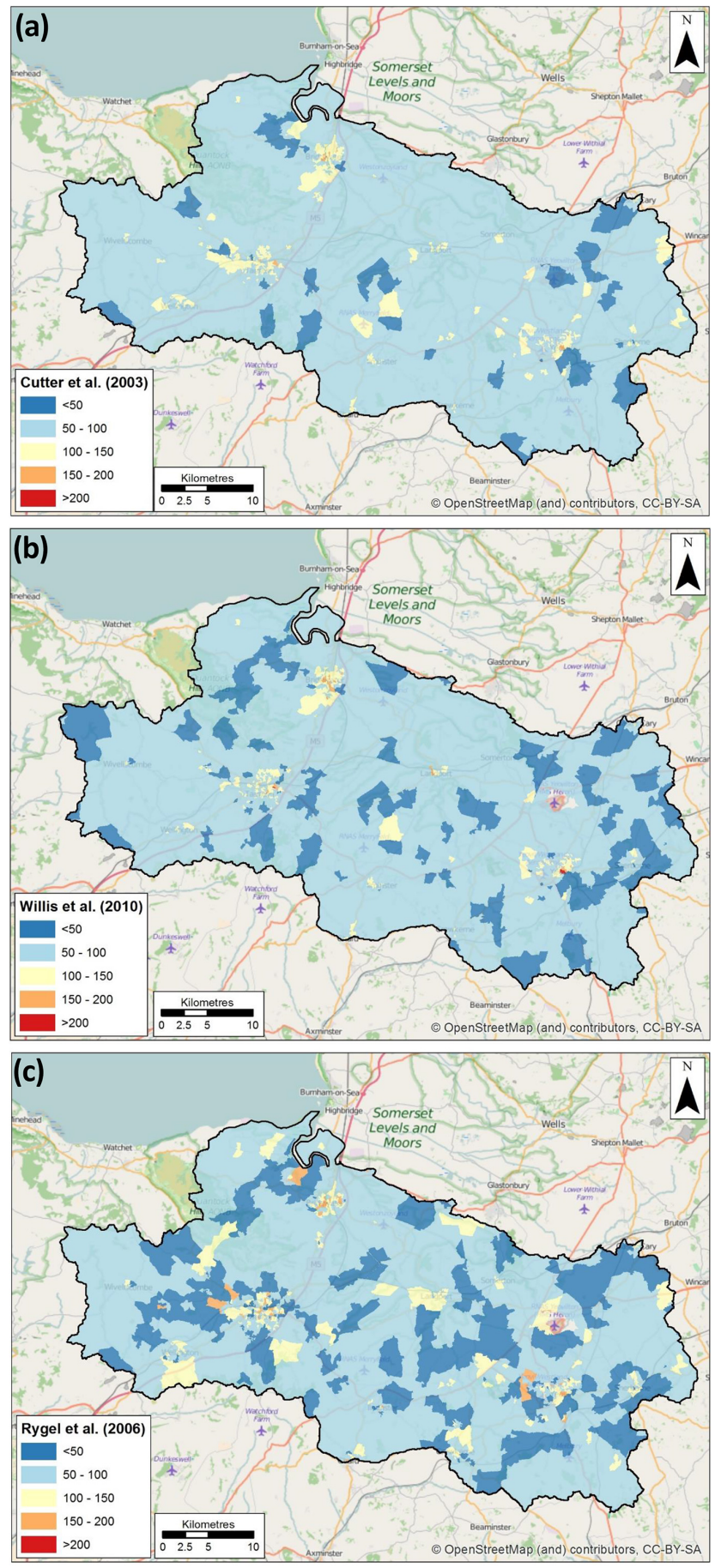

Figure 6. (a) Spatial analysis of social vulnerability index based on the Cutter et al. (2003) methodology for the Parrett catchment, UK. (b) Spatial analysis of social vulnerability index based on the Willis et al. (2010) methodology for the Parrett catchment, UK. (c) Spatial analysis of social vulnerability index based on the Rygel et al. (2006) methodology for the Parrett catchment, UK.
The distribution of social vulnerability in the Parrett catchment is repeated at the smaller scale when an assessment of the output areas that experienced flooding in 2013/2014 flood are considered (flood extent is shown in Fig. 1). The flooding impacted upon a total of 73 output areas with the majority (67) of these output areas categorised as "rural residents" according to the OAC2011 Supergroup classification (Table 6). The average social vulnerability score across the three methods within the rural residents classification is 67.6, considerably below the England and Wales mean score of 100. This assessment demonstrates that the people impacted by the flooding in 2013/2014 would most likely be considered to be less vulnerable than the majority of the England and Wales population. Using a smaller spatial scale to compare the three methods shows that a relatively consistent interpretation about the social vulnerability can be derived. However, as with the Parrett catchment analysis, the Rygel et al. (2006) method has a higher standard deviation than the two other methods. This is supported by Fig. 7, which shows that the social vulnerability score derived from the Rygel et al. (2006) method of individual output areas is extremely erratic, whereas the Cutter et al. (2003) and Willis et al. (2010) methods show a more consistent relationship.

\section{Conclusion}

This research demonstrates the complexity in quantitatively defining the "at risk" population in terms of social vulnerability to flood, as well as natural hazards more generally. When applying alternative methodologies to standardised variable data in a confined geographical setting, differences in the classification and interpretation of the most vulnerable are shown to be evident. The three methods presented within the study are consistent when considering the mean scores and interpreting the general picture of social vulnerability within a geographic area. However, at the level of census output area level, the method based on the Rygel et al. (2006) method produces a social vulnerability classification that differs markedly from the results of Cutter et al. (2003) and Willis et al. (2010). The study showed that the application and subsequent decision-making on the basis of PCA results can lead to the creation of very different, but equally plausible, methodologies to define vulnerable populations within the same study area. The subjective choices of whether to apply Pareto ranks, PCA rotation, and summation methods are just small examples of the relative impact such technical decisions may have on both the locality and quantification of risk value. For example, Pareto ranking used within the Rygel et al. (2006) method was shown to lead to greater heterogeneity of scores but arguably less precision in the quantification of risk. The application of a Gini coefficient used by Willis et al. (2010) may lead to data outliers through the exponential loading of higher or lower vulnerability scores, though the concept of an inclusive methodology could ar- 


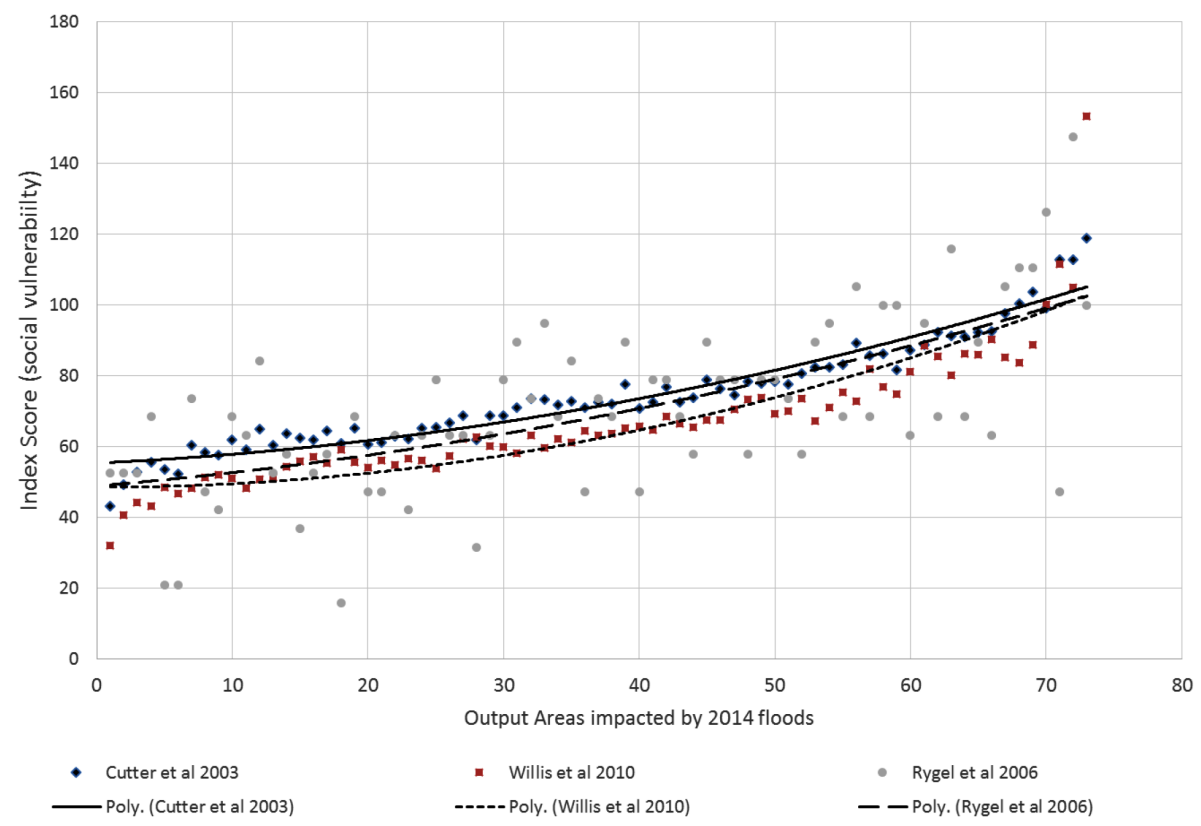

Figure 7. Output area comparison of social vulnerability index scores for the areas impacted by the 2013/2014 flooding.

guably be more relevant than the selection bias of other approaches based on the PCA cardinality.

Whilst recognising the uncertainty that various statistical methods impose on indices, it is critical to note that the fundamental qualitative indicator-based assumptions underlining social vulnerability concepts are arguably the greatest source of uncertainty. Transferring evidence of variable correlation from historic disaster experience to alternative geographies, cultures, and natural hazards leads to an a priori approach with systemic uncertainty. Though qualitative evidence may be grounded in strong correlations between statistical indicators (e.g. socioeconomic or ethnographic) and the polarisation of disaster experience during a given catastrophic event, there is inherent uncertainty as to whether such indicators can be successfully applied in a predictive model in another setting (whether temporal or spatial).

Despite the media coverage and subsequent management of the Parrett catchment after the 2013/2014 flooding, the OAC classifications and vulnerability indices presented here do not regard this population as being more vulnerable than the England and Wales average. Using the "number of persons per hectare" indictor with vulnerability increasing with population density results in underestimating social vulnerability in rural settings. Therefore, it is important to be mindful that the differences highlighted in the methodologies of this paper are just one aspect of the complexity involved in defining social vulnerability. To further investigate the influence the methodological approach has on the classification of social vulnerability, additional research is required to assess a range of different natural hazards, using a greater number of vulnerability indicators over a range of spatial scales.
The findings of this study have implications in both how we convey the uncertainty of such vulnerability assessments as well as in the wider concern of UK flood defence management. Social vulnerability scores or metrics are typically provided as absolute values but, as this study has shown, there are numerous, equally plausible, statistical methods that can lead to very different interpretations about the vulnerability of the same population group. Similarly, in the wake of the December 2015 flooding in Yorkshire and Cumbria, as well as the Somerset floods of 2013/2014, such research can help further inform local and national stakeholder debate as to where UK flood defence funding is best focused to help serve the most disadvantaged. Similarly, social vulnerability indices focused on flood risk (Lindley et al., 2011) can help advise on the issue of localism, regarding where government spending or private-public partnerships could best serve a community in terms of flood risk management (Thaler and Priest, 2014).

Acknowledgements. The authors would like to thank their respective academic institutions as well as JBA Risk Management Ltd for their support during the conduct of this research. Similarly, many thanks to the anonymous referees and Sven Fuchs for the valuable and timely feedback.

Edited by: S. Fuchs

Reviewed by: two anonymous referees 


\section{References}

Adger, W. N., Brooks, N., Bentham, G., and Agnew, M.: New indicators of vulnerability and adaptive capacity, Tyndall Centre for Climate Change Research Technical Report, Tyndall Centre for Climate Change Research, Tyndall, P15-P19, 2004.

Bellù, L. G. and Liberati, P.: Inequality analysis: The gini index, EASYPol Module, FAO, 40 pp., http://www.fao.org/docs/ up/easypol/329/gini_index_040en.pdf (last access: June 2016), 2006.

Birkmann, J.: Measuring vulnerability to promote disaster-resilient societies: Conceptual frameworks and definitions. Measuring vulnerability to natural hazards: Towards disaster resilient societies, United Nations University Press, 1, 9-54, 2006.

Birkmann, J., Cardona, O. D., Carreño, M. L., Barbat, A. H., Pelling, M., Schneiderbauer, S., Kienberger, S., Keiler, M., Alexander, D., Zeil, P., Welle, T.: Framing vulnerability, risk and societal responses: the MOVE framework, Nat. Hazards, 67, 193-211, doi:10.1007/s11069-013-0558-5, 2013.

Bolin, R., Jackson, M., and Crist, A.: Gender inequality, vulnerability, and disaster: Issues in theory and research. The gendered terrain of disaster: Through women's eyes, Canberra, Australia, 8-16, https://www.researchgate.net/publication/257343322_ Quantifying_Social_Vulnerability_A_methodology_for_ identifying_those_at_risk_to_natural_hazards (last access: June 2016), 1998.

Boruff, B. J., Emrich, C., and Cutter, S. L.: Erosion Hazard Vulnerability of US Coastal Counties, J. Coast. Res., 21, 932-942, doi:10.2112/04-0172.1, 2005.

Brooks, N.: Vulnerability, risk and adaptation?: A conceptual framework, Tyndall Working Paper No. 38, Tyndall Centre for Climate Change Research, 1-16, 2003.

Burton, I., Kates, R. W., and White, G. F.: The Environment as Hazard, 2nd Edn., Guilford Press, New York, 1993.

Chakraborty, J., Tobin, G. A., and Montz, B. E.: Population evacuation: assessing spatial variability in geophysical risk and social vulnerability to natural hazards, Nat. Hazards Rev., 6, 23-33, 2005.

Chatterton, J., Clarke, C., Daly, E., Dawks, S., Elding, C., Fenn, T., Hick, E., Miller, J., Morris, J., Ogunyoye, F., and Salado, R.: The costs and impacts of the winter 2013 to 2014 floods, Environment Agency, UK Government, 5-6, 2016.

Clark, G. E., Moser, S. C., Ratick, S. J., Dow, K., Meyer, W. B., Emani, S., Jin, W., Kasperson, J. X., Kasperson, R. E., and Schwarz, H. E.: Assessing the vulnerability of coastal communities to extreme storms: The case of reverse, MA., USA, Mitig. Adapt. Strat. Global Change, 3, 59-82, doi:10.1023/A:1009609710795, 1998.

Coghlan, A.: Dredging would not have stopped massive UK floods, New Scientist, 221, 6, doi:10.1016/S0262-4079(14)60294-3, 2014.

Cutter, S. L., Boruff, B. J., and Shirley, W. L.: Social Vulnerability to Environmental Hazards, Social Sci. Quart., 84, 242-261, 2003.

Cutter, S. L., Boruff, B. J., and Shirley, W. L.: Social vulnerability to Environmental Hazards, in: Hazards, Vulnerability, and Environmental Justice, Praeger, Westport, 115-132, 2006.

Cutter, S. L., Barnes, L., Berry, M., Burton, C., Evans, E., Tate, E., and Webb, J.: A place-based model for understanding commu- nity resilience to natural disasters, Global Environ. Change, 18, 598-606, 2008.

Dilley, M.: Natural disaster hotspots: a global risk analysis, in: Vol. 5, World Bank Publications, The International Bank for Reconstruction and Development, The World Bank, 1-184, 2005.

Dow, K. and Cutter, S. L.: Emerging hurricane evacuation issues: hurricane Floyd and South Carolina, Nat. Hazards Rev., 3, 1218, 2002.

Dwyer, A., Zoppou, C., Nielsen, O., Day, S., and Roberts, S.: Quantifying Social Vulnerability: A methodology for identifying those at risk to natural hazards, 2004/14, Geoscience Australia, Routledge, London, Sterling, VA, https://www.amazon.co.uk/ Hazards-Vulnerability-Environmental-Justice-Earthscan/dp/ 1844073114 (last access: June 2016), 2004.

Elliott, J. R. and Pais, J.: Race, class, and Hurricane Katrina: Social differences in human responses to disaster, Social Sci. Res., 35, 295-321, 2006.

England, K. and Knox, K.: Targeting flood investment and policy to minimise flood disadvantage, Joseph Rowntree Foundation, York, 2015.

Environment Agency: Managing Flood Risk: Parrett Catchment Flood Management Plan, December 2009, https://www.gov. uk/government/uploads/system/uploads/attachment_data/file/ 295642/Parrett_Catchment_Flood_Management_Plan.pdf (last access: 10 May 2016), 2009.

Environment Agency: Effectiveness of additional dredging, December 2010, available at: https://www.gov.uk/government/ uploads/system/uploads/attachment_data/file/392471/The effectiveness_of_dredging_elsewhere.pdf (last access: 1 February 2016), 2014.

Environment Agency: Somerset Level and Moors: Reducing the risks of flooding, available at: https://www.gov.uk/government/publications/ somerset-levels-and-moors-reducing-the-risk-of-flooding/ somerset-levels-and-moors-reducing-the-risk-of-flooding, (last access: 29 January 2016), 2015.

Fuchs, S.: Susceptibility versus resilience to mountain hazards in Austria - paradigms of vulnerability revisited, Nat. Hazards Earth Syst. Sci., 9, 337-352, doi:10.5194/nhess-9-337-2009, 2009.

Füssel, H. M.: Vulnerability: a generally applicable conceptual framework for climate change research, Global Environ. Change, 17, 155-167, 2007.

Gastwirth, J. L.: The Estimation of the Lorenz Curve and Gini Index, Rev. Econ. Stat., 54, 306-316, 1972.

Hartmuth, G.: Ansätze und Konzepte eines umweltbezogenen gesellschaftlichen Monitoring. Ziele, Moeglichkeiten und Probleme eines gesellschaftlichen Monitorings, MAB-Mitteilungen, 42, 9-33, 1998.

Johnson, J. and Zeigler, D.: Evacuation Planning for Technical Hazards: An Emerging Imperative, Cities, 3, 148-156, 1986.

Jolliffe, I. T.: Principal Component Analysis, Second Edition, Encyclop. Stat. Behav. Sci., 30, 487, doi:10.2307/1270093, 2002.

Kuhlicke, C., Scolobig, A., Tapsell, S., Steinführer, A., and De Marchi, B.: Contextualizing social vulnerability: findings from case studies across Europe, Nat. Hazards, 58, 789-810, 2011.

Lew, E. O. and Wetli, C. V.: Mortality from hurricane Andrew, J. Forensic Sci., 41, 449-452, 1996. 
Lindley, S., Neill, J. O., Kandeh, J., Lawson, N., Christian, R., and Neill, M. O.: Climate change, justice and vulnerability, Joseph Rowntree Foundation, 31-34, https://www.jrf.org. uk/report/climate-change-justice-and-vulnerability (last access: June 2016), 2011.

McMaster, R. B. and Johnson Jr., J. H.: Assessing community vulnerability to hazardous materials with a geographic information system, in: Autocarto 8 Proceedings, American Society for Photogrammetry and American Congress on Surveying and Mapping, Falls Church, VA, 471-480, 1987.

Morrow, B. H.: Identifying and Mapping Community Vulnerability, Disasters, 23, 1-18, 1999.

Myers, C. A., Slack, T., and Singelmann, J.: Social vulnerability and migration in the wake of disaster: The case of Hurricanes Katrina and Rita, Populat. Environ., 29, 271-291, 2008.

Nelson, K. S., Abkowitz, M. D., and Camp, J. V.: A method for creating high resolution maps of social vulnerability in the context of environmental hazards, Appl. Geogr., 63, 89-100, doi:10.1016/j.apgeog.2015.06.011, 2015

O'Keefe, P., Westgate, K., and Wisner, B.: Taking the naturalness out of natural disasters, Nature, 260, 566-567, 1976.

Pulido, L.: Rethinking Environmental Racism: White Privilege and Urban Development in Southern California, Ann. Assoc. Am. Geogr., 90, 12-40, 2000.

Reich, U. P.: Gesamtwirtschaftliche Wohlfahrtsmessung und Umweltqualität: Beitr ägezur Weiterentwicklung der volkswirtschaftlichen Gesamtrechnungen, Campus, Frankfurt a. M., 1983.

Reid, C. E., O’Neill, M. S., Gronlund, C. J., Brines, S. J., Brown, D. G., Diez-Roux, A. V., and Schwartz, J.: Mapping community determinants of heat vulnerability, Environ. Health Perspect., 117, 1730-1736, 2009.

Rygel, L., O’Sullivan, D., and Yarnal, B.: A Method for Constructing a Social Vulnerability Index, Mitig. Adapt. Strat. Global Change, 11, 741-764, 2006.

Schaller, N., Kay, A. L., Lamb, R., Massey, N. R., Van Oldenborgh, G. J., Otto, F. E., et al.: Human influence on climate in the 2014 southern England winter floods and their impacts, Nat. Clim. Change, 6, 627-634, 2016.

Somerset County Council: The Somerset Levels and Moors Flood Action Plan, available at: https://somersetnewsroom.files. wordpress.com/2014/03/20yearactionplanfull3.pdf (last access: 3 February 2016), 2014.

Tapsell, S. M., Penning-Rowsell, E. C., Tunstall, S. M., and Wilson, T. L.: Vulnerability to flooding: health and social dimensions, Philos. T. Roy. Soc. A, 360, 1511-1525, doi:10.1098/rsta.2002.1013, 2002.
Thaler, T. and Levin-Keitel, M.: Multi-level stakeholder engagement in flood risk management - A question of roles and power: Lessons from England, Environ. Sci. Policy, 55, 292-301, doi:10.1016/j.envsci.2015.04.007, 2016.

Thaler, T. and Priest, S.: Partnership funding in flood risk management: new localism debate and policy in England, Area, 46, 418425, 2014.

Tomlinson, C. J., Chapman, L., Thornes, J. E., and Baker, C. J.: Including the urban heat island in spatial heat health risk assessment strategies: a case study for Birmingham, UK, Int. J. Health Geogr., 10, 42, 2014.

UNISDR: Hyogo framework for action 2005-2015: building the resilience of nations and communities to disasters, in: A/CONF. 206/6, Extract from the final report of the World Conference on Disaster Reduction, 18-22 January 2005, Kobe, Hyogo, Japan, 2005.

Vickers, D., Rees, P., and Birkin, M.: Creating the National Classification of Census Output Areas: data, methods and results, Working Paper 05/2, School of Geography, University of Leeds, Leeds, http://www.geog.leeds.ac.uk/wpapers/05-2.pdf (last access: 15 May 2012), 2005.

Wallace, M. and Denham, C.: The ONS classification of local and health authorities of Great Britain, in: Studies on Medical and Population Subjects, HM Stationary Office, http://www.ons.gov.uk/ons/guide-method/geography/ products/area-classifications/ns-area-classifications/index/ methodology-and-variables/wards/methodology.pdf (last access: June 2016), 1996.

Watts, M. J. and Bohle, H. G.: The space of vulnerability: the causal structure of hunger and famine, Prog. Human Geogr., 17, 43-67, doi:10.1177/030913259301700103, 1993.

Werner, E. E. and Smith, R. S.: Kauai's children come of age, University Press of Hawaii, Honolulu, 1977.

Willis, I., Gibin, M., Barros, J., and Webber, R.: Applying neighbourhood classification systems to natural hazards: a case study of Mt Vesuvius, Nat. Hazards, 70, 1-22, 2010.

Wisner, B., Blaikie, P., Cannon, T., and Davis, I.: At Risk: natural hazards, people's vulnerability and disasters, 2nd Edn., Routledge, London, UK, 87-118, 2004.

Yoon, D. K.: Assessment of social vulnerability to natural disasters: a comparative study, Nat. Hazards, 63, 823-843, doi:10.1007/s11069-012-0189-2, 2012.

Zakour, M. J. and Gillespie, D. F.: Community Disaster Vulnerability, Springer, New York, NY, doi:10.1007/978-1-4614-5737-4, 2013. 